\title{
Turbulencia Epistémica, Encierros Disciplinares y Corrimiento Decolonial ${ }^{1}$ Vertigem Epistêmica, Fechamentos Disciplinares e Deslocamento Decolonial
}

\author{
MARÍA EUGENIA BORSANI \\ Universidad Nacional del Comahue - CEAPEDI \\ borsanime@ceapedi.com.ar
}

\section{RESUMEN}

Este artículo pondrá en tensión la idea del encierro disciplinar en concomitancia con la escisión naturaleza-cultura. Los blindajes disciplinares, propios de finales del S. XIX y radicalizados en el siglo siguiente, guardan directa relación con la dimensión ontológica, al diferenciar y distanciar el universo de lo "natural" con y respecto al mundo de la "cultura". En esto texto interesa desandar cómo esa separación entre dos órdenes - que ha procurado que ningún o escaso vínculo se establezca entre uno y otro - ha sido servicial a una concepción de mundo moderno-colonial y ciertamente, capitalista, por lo que es menester poner en escena su alcance epistémico-político en simultaneidad con la tematización ontológica de la división cultura-naturaleza.

Palabras clave: Turbulencia epistémica. Encierros disciplinares. Corrimiento decolonial.

\section{RESUMO}

No presente artigo se colocará em questionamento a ideia de fechamento disciplinar e sua relação com a separação entre natureza e cultura. As blindagens disciplinares, próprias do final do século XIX e reforçados no século seguinte, ostentam uma ligação direta com a dimensão ontológica ao diferenciar e distanciar o universo do "natural" no que diz respeito do mundo da "cultura". Neste texto interessa desvendar como essa separação entre duas ordens - que tem procurado que o vínculo estabelecido entre elas seja escassa ou nenhuma - tem favorecido a uma concepção do mundo moderno-colonial e certamente, capitalista, pelo qual é necessário trazer à baila seu alcance epistêmico-político simultaneamente com a tematização ontológica da divisão cultura-natureza.

Palavras-chave: Vertigem epistêmica. Fechamentos disciplinares. Deslocamento decolonial.

\section{ENCIERROS DISCIPLINARES Y ADMINISTRACIÓN DEL CONOCIMIENTO}

Primera afirmación "Aire de familia": los encierros disciplinares son parientes cercanos del individualismo liberal.

Es sabido que el siglo XX tomó en sus manos la tarea de organizar epistémicamente el mundo, un cajón, un estante, para cada cuestión, bien catalogado, y así una clasificación, organización y administración del saber que, en principio, se celebró conforme los campos del

\footnotetext{
${ }^{1}$ Artigo submetido para avaliação em 20/04/2021 e aprovado em 30/04/2021.
} 
Rev. Interd. em Cult. e Soc. (RICS), São Luís, v. 7, n. 1, p. 44- 55, jan./jun. 2021

ISSN eletrônico: 2447-6498

conocimiento se iban expandiendo y las ramificaciones junto a las especialidades iban ganando terreno. Como si acaso fragmentos de mundo y temas- problemas hubieran sido ubicados en una gigante mesa para su quirúrgica disección y posterior acomodamiento en la gaveta correspondiente. Fue sobre mediados del siglo pasado y conforme se iban generando entramados de saberes complejos que se produjeron nuevos campos gestados en ese empeño organizativo con intención ciertamente disciplinaria.

Ahora bien, puede pensarse que encapsular cada disciplina en su propio fuero sin entrecruces ni involucramientos con otros campos del conocimiento, con el propósito de acrecentar la experticia de cada área, contribuye a un encierro que implica la construcción de guetos epistémicos. Es decir, más allá de que se gestaron nuevas parejas epistémicas que reclamaron para sí soberanía disciplinar, lo cierto es que en esos campos se replicó la práctica científica de siempre, el encierro, la experticia, el aislamiento epistémico. Hablamos los unos con los propios y nunca con los otros, o lo que es peor, diseñamos quién es el otro que habita fuera de nuestras amuralladas disciplinas y que nada nadie tiene que venir a decir. Hablamos con los habitantes de nuestro barrio y poco o nada con vecinos-temas-problemas que consideramos son ajenos.

Quienes nos dedicamos al ámbito de las ciencias sociales y humanas entendemos que otros serán los que se ocupen de cuestiones que quedan por fuera de nuestras inspecciones e intereses, todo esto dicho con ironía, ciertamente.

Al respecto recuérdese que sobre mediados del siglo pasado se procuraron diversas taxonomías de los campos científicos. Así, la clasificación hegemónica hizo que el mundo del saber quedara segmentado en grandes parcelas $^{2}$, distinción sostenida prioritariamente en la ontología de base, es decir, en cuál es el tipo de entidades a ubicar en los cajones de uno y otro de los campos. Asimismo, recuérdese al respecto lo que afirmó Immanuel Wallerstein: "La denominación de las disciplinas -es decir, la estructura de la presunta división de la labor intelectual- reflejaba en gran medida el triunfo de la ideología liberal. Esto, por supuesto debido a que dicha ideología liberal fue (y es) la ideología reinante de la economía-mundo capitalista" (WALLERSTEIN, 1998, p. 22).

Dicho esto, que claramente es sólo un rápido e insuficiente mapeo de las grandes diferenciaciones epistémicas de las que somos herederos, me interesa retomar la afirmación con la que abrí este apartado que denominé “aire de familia”. En mi país se dice así cuando el parentesco sale a la luz, cuando se hace evidente, cuando es imposible disimular la

\footnotetext{
${ }^{2}$ Repárese en la distinción entre las ciencias formales y las fácticas y dentro de estas últimas, la diferenciación entre las ciencias naturales y las sociales.
} 
Rev. Interd. em Cult. e Soc. (RICS), São Luís, v. 7, n. 1, p. 44- 55, jan./jun. 2021

ISSN eletrônico: 2447-6498

procedencia compartida. La afirmación que reitero dice así: los encierros disciplinares son parientes cercanos del individualismo liberal.

Ciertamente los derroteros epistémicos son políticos, ello es indudable, y es indubitable también decir que los encierros a los que me he venido refiriendo ocurren en concomitancia con el paulatino encierro de los cuerpos y las cuerpas procurado por el liberalismo ayer y neoliberalismo hoy. Subjetividades aisladas (y no estoy hablando del covid 19) en el mayor de los confinamientos socio-políticos acariciando paradójicamente las bondades del capitalismo bajo el mito del imperio de las libertades plenas. Progresivamente y en simultaneidad con los procesos epistémicos mencionados se va dando una suerte de gradual descreimiento en la comunidad, al menos en una parte significativa de los sectores occidentales, en su franja media, urbana, citadina. Conforme transcurrieron las dos últimas décadas se fueron diseñando diversos dispositivos digitales que sin duda proveyeron beneficios pero también contribuyeron a consolidar el propósito de debilitamiento de tramas comunales y la idea misma de comunidad quedó en el arcón de los recuerdos para cierta parte de la sociedad. El éxito personal, la competitividad, el individualismo llevado a su máxima expresión junto a la idea de "superación personal", del "tu puedes" (que nos des-vincula respecto del mundo y su conflictividad) fue tomando mayor ímpetu hasta posicionarse como idea directriz en el escenario de nuestro tiempo en sociedades occidentales, sobre todo en las grandes ciudades. Así también y en simultaneidad, la literatura de auto-ayuda se volvió un boom (siniestro, por cierto) y los cuerpos y las cuerpas fueron incrementando su encierro y blindaje que no se ciñe a una literalidad sino que remite subjetividades replegadas sobre sí. Se instala así la idea de la autorrealización personal, individual, menoscabando el entorno y el entramado comunal.

\section{UN ANTECEDENTE DE ESTA ALIANZA}

Llegados a este punto, interesa ver un antecedente de esta trama entre los encierros disciplinares y el individualismo capitalista. Podríamos entonces decir que esa disección disciplinar es deudora del movimiento de encierro solipsista del yo pienso cartesiano replegado sobre sí mismo en simultaneidad con el ascenso y auge del escenario liberal siglos después, en estado incipiente por entonces.

Hace ya un tiempo escribí que 
Rev. Interd. em Cult. e Soc. (RICS), São Luís, v. 7, n. 1, p. 44- 55, jan./jun. 2021 ISSN eletrônico: 2447-6498

[...] [f]ue el racionalismo cartesiano el que encerró el conocimiento en el ámbito del yo, del individuo, desprovisto entonces de la dimensión comunal o grupal, como ocurría allá lejos de Europa, en tierras de las Indias tan occidentales como accidentales, según lo expresa un investigador canadiense. Se decretó que quien conoce es el sujeto de conocimiento, nunca una comunidad, claro... desconocía Descartes, por aquellos tiempos, de la existencia de grupos humanos que no tenían en su léxico ni en su ponderación del saber la dimensión del yo, sino la del nosotros. Pero la petulancia de la modernidad adoptó el modelo racionalista y ponderó su aptitud a escala universal. Pues si hay quienes no saben del yo, que lo sepan, ordena la racionalidad moderna eurocentrada!

Se ocultó así el conocimiento en el ostracismo del yo y fue aquel tiempo que Europa lo entendió como magnífico- ciertamente fatídico para la humanidad. Fue también ese momento epocal responsable de la escisión hombre-naturaleza, concomitante al método analítico y como consecuencia de ello, el desguace y fragmentación del mundo y manejo antojadizo del conocimiento y con ello la estructura arbórea del saber. Tal diferenciación ontológica hizo que la naturaleza quedara puesta en el espacio de la exterioridad, de la ajenidad, de una extranjería tal que permitirá en más manipularla, expoliarla conforme la avaricia irrefrenable de la moderna empresa conquistadora y depredadora. (BORSANI, 2011, p. 226)

Sirva entonces este recordatorio cartesiano para entender entonces, casi arqueológicamente, el antecedente de la alianza a la que nos hemos referido respecto a fragmentación disciplinar por un lado y los procesos de subjetivación que se dan el marco del liberalismo, por el otro.

\section{FRACASO O ÉXITO DEL BLINDAJE DISCIPLINAR}

Segunda afirmación "Compleja procedencia": la crisis actual es civilizatoria y no es patrimonio de ningún campo epistémico y lo es de todos.

En los últimos tiempos (difícilmente sería acertado precisar años, pero estimativamente podríamos decir las últimas dos décadas y algo más) nos vemos involucrados en una situación de extrema gravedad que viene recibiendo denominaciones diversas: ocaso de occidente y occidente enfermo (Luis Sáez Rueda); crisis terminal del capitalismo (Pablo González Casanova), crisis civilizatoria (Edgardo Lander), etc. Nos hallamos en una coyuntura que no tiene nada de episódica, coyuntural y tiene todo de sistémica, integral, por ello civilizatoria. A este estado de cosas que se le llama crisis le caben todas las dimensiones que pudiéramos imaginar: hídrica, energética, hidrocarburífera, alimentaria, demográfica, migratoria, educativa, sanitaria, crisis del mundo diseñado, preponderantemente, en el marco las democracias modernas liberales, crisis a escala planetaria, crisis humanitaria. Ninguna de las crisis tiene carácter circunstancial. Sin duda es un modo de ordenamiento del mundo el 
Rev. Interd. em Cult. e Soc. (RICS), São Luís, v. 7, n. 1, p. 44- 55, jan./jun. 2021

ISSN eletrônico: 2447-6498

que estalla, el que colapsa, el que detona. Son las promesas y premisas moderno-coloniales que naufragaron una a una, se desenmascaró la ficción, la mentira, se visibilizó el reverso colonial de la modernidad, siguiendo aquí el planteo de Walter Mignolo (2007). Quedó al descubierto la indisimulable apetencia de apropiación/expropiación de seres y saberes, quedó expuesta la colonialidad como envés de la modernidad. Se volvió indisimulable el lado oscuro constitutivo de la modernidad y condición de posibilidad, la lógica de la colonialidad. Y al mismo tiempo quedó al descubierto que ninguna de las disciplinas, que ningún campo disciplinar fue lo suficientemente permeable respecto a las veces que se alertó acerca de los riesgos de la fragmentación, segmentación y / o el encierro disciplinar como lo hemos venido mencionando.

Noam Chomsky (2015, n.p.) sostuvo que

El mundo que estamos creando para nuestros nietos es sombrío... El nivel de destrucción de especies en el mundo de hoy se acerca al nivel de hace sesenta y cinco millones de años, cuando un gran asteroide golpeó la Tierra y tuvo efectos ecológicos horripilantes. Lo mismo está sucediendo ahora, excepto que ahora somos nosotros el asteroide.

Ese mundo al que Chomsky hace alusión se vincula con los irreversibles y nocivos cambios generados por el hombre en el planeta (BORSANI, 2018). En el año 2000 un nuevo concepto aparece en escena para dar cuenta del presente del planeta y con ello nombrar una novedad respecto a la edad de la tierra. Se aplica así el término antropoceno a esta nueva era/edad de la tierra, que dejaría atrás el holoceno, inaugurado hace casi 12.000 años atrás ${ }^{3}$.

La novedad geológica sería antropogénica, siendo el hombre quien produjo los cambios dañinos a nivel planetario. Se da un debate respecto al comienzo de antropoceno, si comienza con la revolución industrial o con posterioridad. Sí hay acuerdo respecto a la marca indeleble dejada sobre la corteza terrestre a partir de mediados de siglo pasado por los desechos nucleares e isótopos radiactivos ${ }^{4}$. Cabe señalar que al interior de la comunidad epistémica de la Estratigrafía (abocada al estudio de los estratos rocosos) no hubo pronta

\footnotetext{
${ }^{3}$ El término "antropoceno" aparece de manos de Paul Crutzen quien recibió el Premio Nobel de Química en el año 1995 por sus estudios referidos a la capa de ozono. Interesa saber cómo comenzó a circular este nuevo concepto: Helmuth Trischler, en "El Antropoceno, ¿un concepto geológico o cultural, o ambos?" señala que "Cuando Paul Crutzen y Eugene Stoermer (2000) presentaron por primera vez la idea del Antropoceno en el boletín del Programa Internacional Geósfera-Biósfera (IGBP, por sus siglas en inglés), no podían haber previsto la meteórica trayectoria del Antropoceno. Si lo hubieran sabido, seguramente no habrían publicado su propuesta en un boletín interno, sino en una revista científica prominente para alcanzar a la comunidad científica mundial. Dos años después, Crutzen (2002) rectificó esta omisión cuando presentó su hipótesis en un preciso y sucinto artículo de una página titulado "Geología de la humanidad", en la revista Nature." (Trischler, 2017, p. 41).

${ }^{4}$ Crutzen se inclina a ubicar el antropoceno sobre mediados del Siglo XVIII merced la revolución industrial.
} 
Rev. Interd. em Cult. e Soc. (RICS), São Luís, v. 7, n. 1, p. 44- 55, jan./jun. 2021 ISSN eletrônico: 2447-6498

aceptación de esta novedad conceptual respecto al antropoceno en tanto nueva era geológica y la Comisión Internacional de Estratigrafía (conocida por sus siglas en inglés como ICS $)^{5}$ fue muy cauta en relación a aceptar una nueva tabla cronoestratigráfica (abocada al estudio del tiempo de los estratos).

Sin embargo, aun cuando en el campo específico de la geología las controversias continuaron por tiempo -disputas que ciertamente no son de nuestra incumbencia-, en el campo de las ciencias sociales el concepto antropoceno impacta y recibe incluso lecturas que hacen que dicha denominación sea ajustada/modificada en virtud de las implicancias éticopolíticas de la misma. Es decir, su operatividad escapa al campo de la geología y su impacto en el orden de lo político es tal que pareciera tener sin cuidado las disputas geológicas. Pues está a las claras que nos hallamos ante un nuevo momento epocal y poco importa si se ha refrendado o no como era o período geológico; lo que es indubitable es el nivel de demencial devastación a la que asistimos en nuestros días y los indiscutibles efectos nocivos que la actividad del hombre produjo sobre la tierra, cambiando y alterando su fisonomía e impactando negativamente sobre los seres vivos de modo incontestable, enmascarado bajo la denominación de desastres "naturales". Así, la atribución de "natural" exculpa de todo compromiso con lo acaecido al hombre mismo, no obstante, al decir de Chomsky, es/somos el asteroide que provoca efectos socioambientales horripilantes que dan pavura.

Retomo a continuación el enunciado que anunció la segunda parte de esta conferencia: "la crisis actual es civilizatoria y no es patrimonio de ningún campo epistémico y lo es de todos". Reitero, el concepto mentado gravitó de manera insospechada en el campo de las ciencias sociales y humanas. Los tan mentados encierros disciplinares se perforaron en mil lugares y campos alejados de las áreas de donde procedió el concepto antropoceno pusieron en cuestión qué tan fácilmente se podía endilgar a toda la humanidad ser el agente geológico causante del desastre brutal al que asistimos. O sea, si decimos "hombre" o "la humanidad" ¿nos estamos refiriendo a todos los hombres?, o sea, ¿compromete a toda la humanidad?; ¿Todos los seres humanos por igual y en idéntica medida contribuimos al dantesco y siniestro estado actual? Así fue que el término gestado en ámbitos cercanos a la geología deviene en capitaloceno, entre otras nuevas denominaciones que aceptan la idea del hombre como agente geológico pero lo ponen a cuenta de una responsabilidad muy direccionada al capitalismo y sus efectos. Jason Moore, quien patrocina el concepto capitaloceno, señala que hay:

\footnotetext{
${ }^{5}$ La ICS integra la Unión Internacional de Ciencias Geológicas, conocida por su sigla en inglés, IUGS.
} 
Rev. Interd. em Cult. e Soc. (RICS), São Luís, v. 7, n. 1, p. 44- 55, jan./jun. 2021

ISSN eletrônico: 2447-6498

[...] dos almas en el argumento del Antropoceno. Una es directamente el argumento geológico, que tiene que ver con la búsqueda de los llamados picos dorados y con el examen de señales estratigráficas. El otro argumento, que es el que ha ganado tanta popularidad, consiste en reconfigurar la historia del mundo moderno como la edad del hombre, "el Antropoceno". Este es un viejo truco capitalista: decir que los problemas del mundo son los problemas creados por todos, cuando en realidad han sido creados por el capital. Y es por esto que creo que deberíamos hablar del Capitaloceno, como una era histórica dominada por el capital. (MOORE, 2017 apud WEDEKIND; LILANEZ, 2017, p. 109)

Así entonces, no toda la humanidad, no todos los humanos, no todos los hombres y mujeres hemos contribuido en igual medida al desesperante y espeluznante presente. Y así fue como se precipitó una suerte de turbulencia epistémica, un entrevero de politología, sociología, filosofía, geología, historia, cronoestratigrafía, junto al arte, a activismos varios, a la educación y muchos etcéteras. Revuelta epistémica, pérdida de exclusividad de los campos referidos, tramas indispensables. Fracaso, ciertamente celebratorio, del sueño de la experticia y la especialización radicalizada, urgida de diálogos con vecinos epistémicos.

Dicho de otra manera, echadas a rodar las tesis del antropoceno diversas áreas se vieron instadas a entrar en diálogo con campos que en principio era impensado y viceversa, pues la geología no se imaginó debatiendo con las aristas políticas de las dataciones de los estratos rocosos, volviendo ésta política pues da cuenta de la incidencia del capitalismo y sus consecuencias toman la forma de sedimento. Así las cosas, la certeza que tenemos es que es tal la magnitud de la crisis e involucramiento de ámbitos tan diversos que es imposible que sea abordada desde un único campo. Sólo un entramado complejo, que requiere de la convergencia de ámbitos muy diversos, puede contribuir a, si no revertir, sí a detener los efectos del antropoceno, allí entonces el entrecruce disciplinar se ve inevitable y urgente.

Lo planteado se vuelve entonces un ejemplo claro respecto al fracaso de las corazas disciplinares por una parte, y por la otra muestra la imposibilidad de pensar que la actual crisis que se cierne sobre absolutamente todos los órdenes de la vida humana y no humana pueda ser patrimonio epistémico de una determinada área, por ello es que reiteramos la crisis actual es civilizatoria y no es patrimonio de ningún campo epistémico y lo es de todos.

\section{CELEBRANDO ENREDOS INDISCIPLINADOS}

Tercera afirmación "Corrimientos de escisiones ontológicas": la resemantización de la noción de cultura y la sutura del abismo hombre - naturaleza. 
Rev. Interd. em Cult. e Soc. (RICS), São Luís, v. 7, n. 1, p. 44- 55, jan./jun. 2021 ISSN eletrônico: 2447-6498

Llegado entonces a esta instancia entendemos que los enredos disciplinares son laudatorios y más que importantes son las consecuencias a las que nos lleva esta suerte de entramado epistémico. Lo dicho no está afirmado desde lo que normalmente se denomina interdisciplina ni transdisciplina (que no es sino un forzado diálogo respetando reglas de buena costumbre con campos afines) sino, y muy por el contrario, optamos por la indisciplina o desobediencia epistémica según la opción decolonial (MIGNOLO, 2010; WALSH, 2007; PALERMO, 2013).

Señalamos al menos tres cuestiones en pos de desobediencias, corrimientos y desprendimientos de la matriz/patrón colonial de poder global:

1) Todos los campos epistémicos propios de la academia occidental han sido insuficientes para dar cuenta de la brutal dimensión de la conflictividad actual y lo que es peor, en ciertos casos, cómplices de la actual devastación a nivel planetario.

2) El pensamiento crítico sólo puede concebirse como tal en tanto invierta la direccionalidad y modalidad en la construcción del saber, desmontando la jerarquía académica habitual que va desde el mundo del conocimiento hacia el mundo, sino invirtiendo la lógica investigativa, corriéndose a su vez del solipsismo cognitivo y apuntando al conocimiento como resultante de una actividad colectiva, desafiando así el individualismo liberal.

3) Por último, y como cierre de esta conferencia de apertura de un Posgrado sobre Cultura y Sociedad, y que concierne al desprendimiento aludido, importa poner en tensión la diferenciación naturaleza - cultura y pensar que la ontología ha de venir al relevo de la noción de cultura, cuestión en la que ha insistido Arturo Escobar (2016). Unas líneas a propósito de este tercer punto que toca lo neurálgico de este posgrado: 'Cultura y Sociedad', como lo es el nombre del recorrido curricular que están pronto a emprender. Una lógica binaria separa cultura, por una parte y naturaleza por la otra, diseñando una distancia abismal, concebidas como dos entidades diversas y mientras una remite al universo humano, la otra, naturaleza, refiere a lo que está afuera, en una relación de absoluta ajenidad respecto del universo humano, en un vínculo de total extrañeza y extranjería, instalando así una ontología de la escisión, de la ruptura. Esto no es sino una excelente estrategia propia de la matriz capitalista colonial: la naturaleza está allí y es el hombre quien dispone de ella en tanto recurso a explotar, la naturaleza a expensas de los designios capitalistas en conformidad con el esquema del sistema mundo moderno/colonial. 
Rev. Interd. em Cult. e Soc. (RICS), São Luís, v. 7, n. 1, p. 44- 55, jan./jun. 2021

ISSN eletrônico: 2447-6498

Así, la escisión ontológica entre el mundo de lo humano por una parte, y el mundo natural, a disposición de lo humano por la otra se advierte con claridad y es deudor de esa fragmentación epistémica de la que hablamos al inicio, colonialidad del saber imponiendo criterios y ordenando ámbitos para el posterior dominio de esos mismos saberes.

Por el contrario, la relacionalidad reivindica y despliega una ontología posdualista y pos-occidental; cuestiona la escisión cultura / naturaleza, recusa binomios y debilita la lógica contradictoria propia de la episteme moderna. Con contundencia Arturo Escobar sostiene que

lo que existe es un mundo entero que se enactúa minuto a minuto, día a día,
a través de una infinidad de prácticas que vinculan una multiplicidad de
humanos y no-humanos. Para resumir: una ontología relacional puede
definirse como aquella en que nada (ni los humanos ni los no humanos)
preexiste las relaciones que nos constituyen. Todos existimos porque existe
todo (ESCOBAR, 2015, p. 29).

Por su parte, Rolando Vázquez sostiene que: "la relacionalidad puede contrarrestar y resistir la separación y el vaciamiento que supone el orden de la modernidad. La relacionalidad implica una concepción de tiempo profunda, frente a ella la modernidad aparece como la forma civilizatoria que fragmenta, separa, vacía (VÁZQUEZ, 2014, p. 5). El criterio de una lógica relacional no oposicional es compatible con concepciones de comunidades no-occidentales, quienes no admiten la relación de exterioridad de la naturaleza con respecto al hombre y que hoy están, en buena medida, al frente de significativos movimientos sociales de resistencia, merced la crisis del presente en toda su dimensión, cuya posibilidad de detenimiento o reversión exige de otra ontología que se desprenda de la brecha naturaleza-cultura, pues ese modo de mirar el mundo en términos binarios ha obturado una cabal comprensión de las intencionalidad político- económica que le subyace, que no es otra que exacerbar la idea de la exterioridad de la naturaleza a efectos de maximizar las acciones de saqueo y expoliación.

Finalmente, retomo las hebras ofrecidas para el tejido final. Titulé esta conferencia "Turbulencia epistémica, encierros disciplinares y corrimiento decolonial” y la desarrollé en tres momentos, a saber:

a. Al primer momento lo llamé 'Encierros disciplinares y administración del conocimiento' junto a una primera afirmación bajo el título "Aire de familia": los encierros disciplinares son parientes cercanos del individualismo liberal. 
Rev. Interd. em Cult. e Soc. (RICS), São Luís, v. 7, n. 1, p. 44- 55, jan./jun. 2021 ISSN eletrônico: 2447-6498

b. Al segundo momento lo llamé 'Fracaso o éxito del blindaje disciplinar' junto a una segunda afirmación bajo el título "Compleja procedencia": la crisis actual es civilizatoria y no es patrimonio de ningún campo epistémico y lo es de todos.

c. Al tercer momento lo llamé 'Celebrando enredos indisciplinados' junto a una tercera afirmación bajo el título "Corrimientos de escisiones ontológicas": la resemantización de la noción de cultura y la sutura del abismo hombre - naturaleza.

Como cierre, entiendo que los planteos decoloniales que proponen los corrimientos y desprendimientos aludidos son hoy las más apropiadas rutas críticas para sortear la turbulencia epistémica del presente. Tales corrimientos implican una desmonumentalización de la episteme moderno-colonial, una restricción a las pretensiones de universalidad propias de la ciencia hegemónica, propiciando una transversalización de saberes de procedencias muy diversas en aras de la equidad epistémica y, en consecuencia, una apertura hacia pedagogías críticas (WALSH, 2017).

La decolonialidad, -entendiendo a esta como una tarea y teoría en la que se interpenetran e interfieren las esferas de la conceptualización epistémica y la de la praxis política- insta en primer lugar a un reconocimiento de nuestra propia condición de colonizados y colonizadores al tiempo que es ese mismo momento en el que se genera el giro hacia un horizonte otro que posibilita inteligir el mundo de cara a la conflictividad actual. Como he dicho en Rutas decoloniales, la decolonialidad "[e]s un desplegarse, es una perspectiva que ha de ser pensada y entendida en clave de gerundio, en un siendo que va adquiriendo distintas dimensiones y contornos según se va construyendo. Como norte prefijado, más allá de este "estar conformándose", se avizora la puesta en cuestión del patrón de poder colonial, en tanto matriz de opresión inaugurada con la modernidad" (BORSANI, 2021, p. 71), esta consideración ciertamente deudora de las enseñanzas de Quijano y Mignolo.

Resultas de ello, importa celebrar la turbulencia epistémica y propiciar un balance positivo de los enredos disciplinares referidos toda vez que estos contribuyan a cincelar, esculpir, delinear mundos distintos al que la modernidad nos ha legado por fuera al diseño de muerte inherente a dicho proyecto.

\section{REFERENCIAS}

ANTROPOCENO vs Capitaloceno. Crisis Capitalista, p. 1-2, dez. 2015. Disponible en: http://crisis-capitalista.blogspot.com/2015/12/antropoceno-vs-capitaloceno.html. Acesso em: 19 de março de 2021. 
Rev. Interd. em Cult. e Soc. (RICS), São Luís, v. 7, n. 1, p. 44- 55, jan./jun. 2021 ISSN eletrônico: 2447-6498

BORSANI, María Eugenia. Rutas decoloniales. Buenos Aires: Ediciones del Signo y Duke University, 2021.

BORSANI, María Eugenia. Sobre la mentira de lo natural: tiempos de catástrofes en el desquiciado presente global. In: VALLS, Pierre (Org.) Nueva institucionalidad. Ciudad de México: (con)Tensión editorial, 2018, p. 22-39.

BORSANI, María Eugenia. El proyecto decolonial ante el colapso civilizatorio occidental: ¿el presente exánime de la Filosofía? o la Filosofía ante un presente exánime. In: SÁEZ, Luis Rueda; PÉREZ, Pablo Espigares; HOYOS, Inmaculada Sánchez (ed.). Occidente enfermo. Filosofía y Patologías de Civilización. München: Grin Verlag GmbH, 2011, p. 223-237.

ESCOBAR, Arturo. Autonomía y diseño: la realización de lo comunal. Popayán, CO: Universidad del Cauca, 2016.

ESCOBAR, Arturo. Territorios de diferencia: la ontología política de los "derechos al territorio". Cuadernos de Antropología Social, n. 41, p. 25-38, 2015.

MIGNOLO, Walter. Habitar la frontera: sentir y pensar la descolonialidad (Antología, 1999 - 2014). Barcelona: CIDOB, 2015.

MIGNOLO, Walter. Desobediencia Epistémica. Retórica de la modernidad, lógica de la colonialidad y gramática de la descolonialidad. Buenos Aires: Ediciones del Signo, 2010.

MIGNOLO, Walter. La idea de América Latina. La herida colonial y la opción decolonial. Barcelona: Gedisa, 2007.

PALERMO, Zulma. Desobediencia epistémica y opción decolonial. CECIES. Pensamiento Latinoamericano y Alternativo. Disponible en: http://www.cecies.org/articulo.asp?id=227

PALERMO, Zulma. Desobediencia epistémica y opción decolonial. Cadernos de Estudos Culturais, Campo Grande, MS, v. 5, p. 237-194, jan./jun. 2013.

TRISCHLER, Helmuth. El Antropoceno, ¿un concepto geológico o cultural, o ambos? Revista Desacatos, Ciudad de México, n. 54, 2017, p. 40-57.

VÁZQUEZ, Rolando. Olvido y relacionalidad. SEMINARIO INTERNACIONAL DEL PROGRAMA DE DIÁLOGO NORTE-SUR, "JUSTICIA, CONOCIMIENTO Y ESPIRITUALIDAD”, 17, 2014. San Cristóbal de las Casas, MX. Anais [...]. San Cristóbal de las Casas: Cideci - Unitierra Chiapas, 2014.

WALLERSTEIN, Immanuel. Impensar las ciencias sociales. México: Siglo XXI, 1998.

WALSH, Catherine. Pedagogías decoloniales. Prácticas insurgentes de resistir, (re)existir y (re)vivir. Quito: Abya Yala, Tomo II, 2017.

WALSH, Catherine. ¿Son posibles unas ciencias sociales/culturales otras? Reflexiones en torno a las epistemologías decoloniales. Revista Nómadas, Bogotá, n. 26, p. 102-113, 2007. 
Rev. Interd. em Cult. e Soc. (RICS), São Luís, v. 7, n. 1, p. 44- 55, jan./jun. 2021 ISSN eletrônico: 2447-6498

WEDEKIND, Jonah; MILANEZ, Felipe. Del Capitaloceno a una nueva política ontológica: Entrevista a Jason Moore. Ecología Política, n. 53, p. 108-110, 2017. 